Delft University of Technology

\title{
Direct Tensile Test to Assess Healing in Asphalt
}

Leegwater, Greet; Scarpas, A.; Erkens, S.

DOI

10.3141/2574-14

Publication date

2016

Document Version

Accepted author manuscript

Published in

Transportation Research Record

\section{Citation (APA)}

Leegwater, G., Scarpas, A., \& Erkens, S. (2016). Direct Tensile Test to Assess Healing in Asphalt.

Transportation Research Record, (2574), 124-130. https://doi.org/10.3141/2574-14

\section{Important note}

To cite this publication, please use the final published version (if applicable).

Please check the document version above.

Other than for strictly personal use, it is not permitted to download, forward or distribute the text or part of it, without the consent of the author(s) and/or copyright holder(s), unless the work is under an open content license such as Creative Commons.

\section{Takedown policy}

Please contact us and provide details if you believe this document breaches copyrights.

We will remove access to the work immediately and investigate your claim. 
5 Delft University of Technology

6 Stevinweg 1, 2628CN Delft, The Netherlands

7 Tel: +31 619616630; Email: g.a.leegwater@tudelft.nl

9 Tom Scarpas

10 Delft University of Technology

11 Stevinweg 1, 2628CN Delft, The Netherlands

12 Tel: +31 15 2785066; Email: A.Scarpas@tudelft.nl

13

\section{Sandra Erkens}

15 Delft University of Technology

16 Stevinweg 1,2628CN Delft, The Netherlands

17 Tel: +31 15 2785066; Email: $\underline{\text { S.M.J.G.Erkens@tudelft.nl }}$

Corresponding author:

20 Greet Leegwater

21 g.a.leegwater@tudelft.nl

23 Total number of words:

24 Words in text 3,688

Figures $(8 \times 250)$ 2,000

26 Total word equivalents $\mathbf{5 , 6 8 8}$

27

28

Submission Date:

291 August 2015 


\section{ABSTRACT}

2 Asphalt concrete has the advantageous ability to heal. During rest periods damage present in the

3 material is restored to a certain extent. Healing can be observed in the regain of strength and

4 stiffness of the material after rest periods.

In this paper a new test method is presented that is developed to increase the understanding

6 of the healing phenomenon. The test method focusses on bitumen as it is assumed to be the driver

7 of healing performance. The test method assesses the healing performance of bitumen both in

8 stiffness and strength by testing the bond strength in tensile mode of two pieces of bitumen that are

9 assembled under controlled temperature and stress conditions. Using the test method healing tests

10 are performed on one type of binder, varying the load level during healing and the healing time.

From the test results it can be seen that after a short healing time of only 6 minutes there is

12 already a significant amount of healing detected, implying that the adhesion between two crack

13 surfaces is an important factor which influences the healing capacity. It was also found that the

14 maximum tensile stress increased significantly during 1 week of healing. This indicated that also

15 slow processes like diffusion are expected to have a significant influence on healing. Consequently

16 the importance of considering healing as a combination of wetting and intrinsic healing is

17 demonstrated.

18

19 Keywords: Healing, Bitumen, Intrinsic healing, Wetting, Direct Tensile Test, Keyword 


\section{INTRODUCTION}

Asphalt concrete has the advantageous ability to heal. During rest periods damage present in the material is restored to a certain extent. Healing can be observed in the regain of strength and stiffness of the material after rest periods.

The fact that damage in asphalt can be restored during rest periods has first been reported by Bazin and Saunier [1]. From this moment on the phenomenon is called healing and it is studied ever since [2-4]. It has been demonstrated that the level of healing increases with longer resting periods, higher healing temperatures and a larger force perpendicular to the crack [5]. However, the mechanisms behind healing of asphalt are not fully understood up until now, which impedes full exploitation of this interesting material property.

Healing is only relevant with respect to damage. Many changes in a material can be classified as damage. In asphalt the aging of the material or the ingress of water are types of damage. However, within this research damage is defined as a physical discontinuity in the material. Healing of discontinuities is relevant for asphalt performance as the initiation of micro cracks is one of the causes for the loss of material stiffness in a fatigue test [6]. AFM images have shown that damage on the microscale can manifest itself as micro cracks [7].

In order to understand the mechanisms driving the healing process, researchers in asphalt have adopted the healing model used in polymers [8,9]. Their convolution model can be described as follows; healing of cracks is the sum of two processes. Firstly, in order for surfaces to be able to transfer loads they have to be in contact, this is process of two surfaces coming into contact is referred to as wetting. Secondly, the surfaces in contact have an increasing ability to transfer loads as the material at the interface becomes homogeneous again over time as a consequence of diffusion; this is referred to as intrinsic healing. The macroscopic observed healing is the sum of these processes integrated over the total area where damage is healing. Consequently this model implies that specimens can fully heal if all damaged surfaces are brought into full contact and surface in contact have enough time to fully homogenize.

It should be noted that the definition of intrinsic healing given here deviates slightly from the definition formulated in the area of self-healing materials [10]. The healing that is referred to as intrinsic healing is this research is the healing that can be attributed to diffusion over a crack interface. This intrinsic healing originates from molecular motion at the crack interface, which should not be affected by normal force [8].

Wetting is the process describing how two surfaces come into contact. Contact develops at a very small scale on which all material surfaces show some level of roughness. As a result the contact area will develop from an increasing number of contact points, that each grow over time as is illustrated in FIGURE 1. Influencing factors of wetting are; the external load that brings the surfaces together; the geometry (roughness of the surface); the viscoelastic properties of the material and the adhesion of the material [11]. 


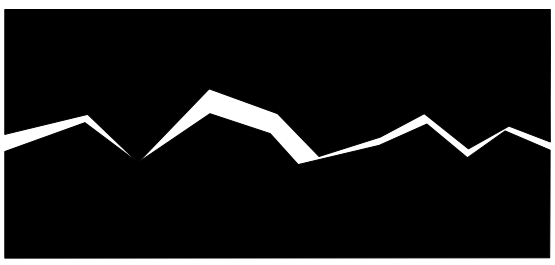

a.

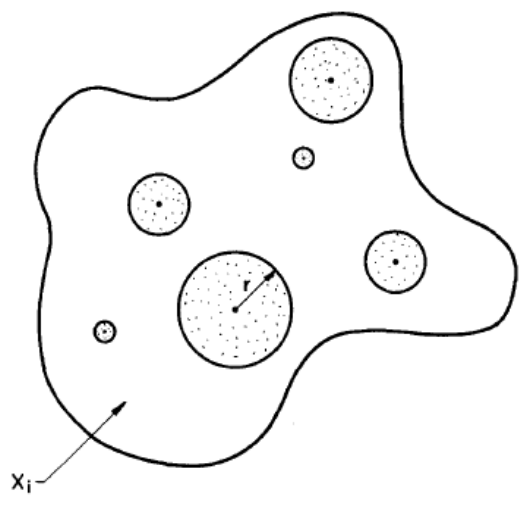

b.

FIGURE 1 a. Cross section of crack area, Right: Development of surface area in contact the dots represent contact area's that develop in the direction of $r$ over time.

In this paper a new test method is presented that is developed to increase the understanding of the healing phenomenon. Asphalt is a heterogeneous material consisting of stone aggregates, filler and bitumen. Of these materials bitumen is expected to be the driving force behind healing of the material. At ambient temperatures bitumen is sticky and has the ability to flow (very slowly), these properties enable bitumen to heal damage. Therefore, to understand healing of asphalt the first step is to understand healing of bitumen, consequently the test method presented in this paper assesses the healing performance of bitumen. Intrinsic healing of bitumen has been studied by other researches in the past, showing the influence of bitumen type, temperature and aging level [4]. They introduce the two piece healing method, that describes how samples of bitumen can be brought into contact and how the increase in shear stiffness with increasing healing time can be determined. One of the limitations of this method is that it only tests the stiffness gain over time and not the development of failure stress.

The new test method presented in the following chapter also aims to measure the intrinsic healing, by bringing two pieces of bitumen into contact. New in this test method is that both failure stress and stiffness are measured. Failure stress is a very important material property with respect to healing as past research on asphalt concrete has shown that a very significant stiffness gain does not imply that a sample has healed in terms of strength or numbers of loads until failure [12].

The aim of the test program run with this new test method is threefold. A test series has been run to asses if the developed test method measures only intrinsic healing or a combination of wetting and intrinsic healing. Next to this healing is assessed over time to obtain a notion of the time scales that are relevant for healing of bitumen. Finally the ratio of strength and stiffness is evaluated to see if their recovery runs in parallel or if stiffness recovery in bitumen is also faster compared to strength recovery as seen in asphalt.

\section{MATERIALS AND METHOD} Materials

All samples tested were made of a pengrade 70/100 bitumen from Q8. This relatively soft bitumen, is regularly used for Dutch roads and consequently for research purposes. Dutch regulations indicate that asphalt concrete made with a bitumen of pengrade 70/100 will have good healing

36 properties. 


\section{Design of The Method}

As already mentioned the damage in asphalt concrete is assumed to be some form of (micro) discontinuity in the material. The test method is designed to investigate the most extreme version of a discontinuity; two separate pieces of bitumen. These two pieces of bitumen are brought together, in a temperature controlled environment. When designing the test method the aim was to create instant full contact between the pieces of bitumen, in other words immediate full wetting. Consequently all healing measured in a test with instant contact over the whole surface area is intrinsic healing. The global set-up of the test method is shown in FIGURE 2, showing bitumen sample design, assembly of samples, healing set-up and tensile testing.

Special bitumen samples were designed. A stainless steel ring is introduced around the bitumen, to allow for handling and fixation during preparation and testing. Size of the ring and bitumen are shown in FIGURE 2 on the left. The bitumen sample has a specific shape to control the amount of contact area during healing, this shape is created with specially designed rubber mould, see FIGURE 3 a and $b$.
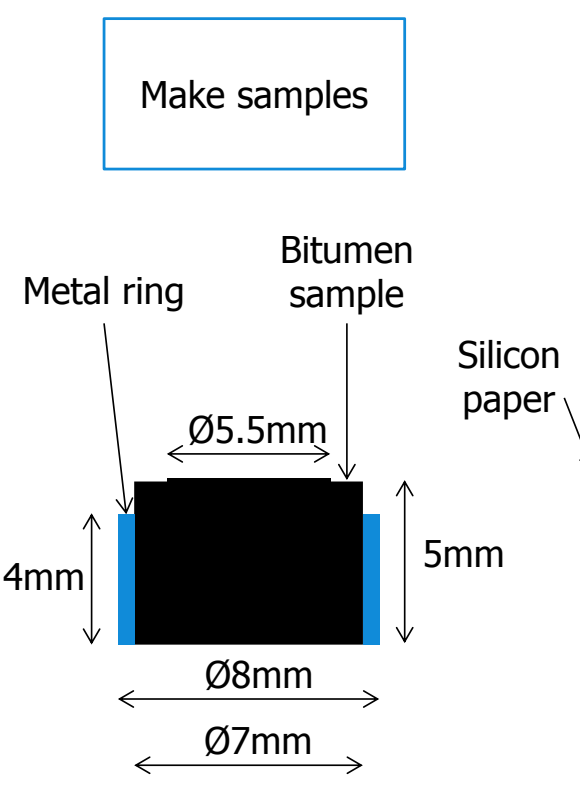
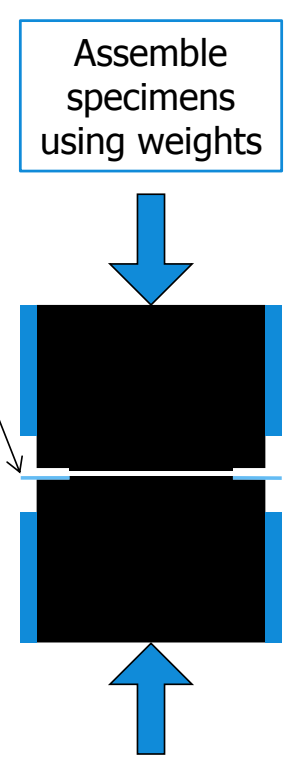
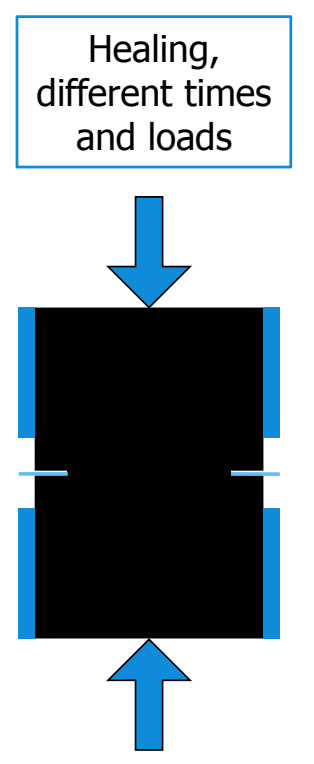
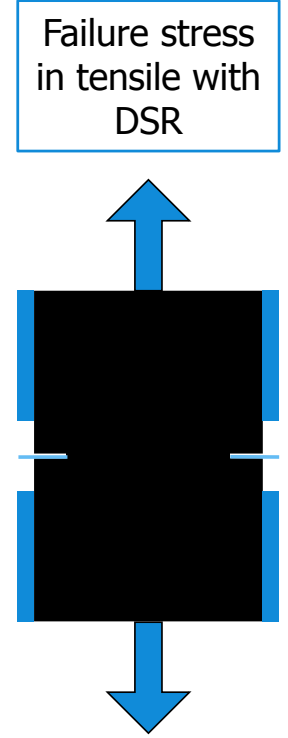

FIGURE 2 Schematic Representation of Test Method, Including Sample Design

For the testing of healing these bitumen samples are assembled, by placing a second sample upside down on the first sample as illustrated on the second image in FIGURE 2. The pressure during assembly is controlled using weights; the contact area is controlled using a round piece of silicon paper with a small hole of $\varnothing 5.5 \mathrm{~mm}$. After assembly the specimens are stored under controlled temperature conditions to heal for different periods of time. The weights used in assembly are kept in place during storage. To assess the quality of contact a micro tomography scan was made of an assembled specimen, no air bubbles were seen in the contact area.

After the healing period specimens are tested under controlled conditions in direct tension using a DSR equipped with a normal force load cell (Anton Paar, EC Twist 502). 


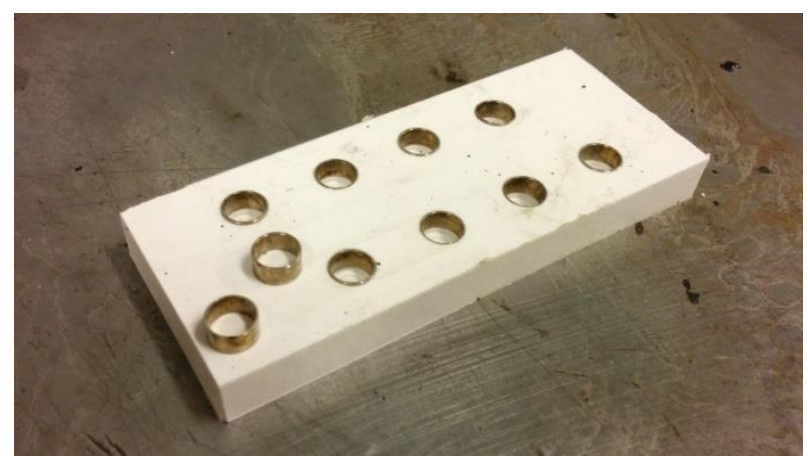
a.

FIGURE 3 a. Sample Mould With Metal Rings In Place, just before bitumen is poured in the mould. b. Bitumen Sample Before Assembly.

\section{Sample Preparation}

The bitumen and the mould with the metal rings in place are heated for one hour at $165^{\circ} \mathrm{C}$, next the bitumen is poured in the mould. The mould with bitumen samples is left to cool for 1 hour in the freezer at $-24^{\circ} \mathrm{C}$. The bitumen samples are up-side-down in the mould. After cooling the excess bitumen is removed from the top of mould, so that the bitumen exactly fits the ring. The sample is left to cool again at $-24^{\circ} \mathrm{C}$ until demolding. Demolding is done under controlled temperature conditions $\left(13^{\circ} \mathrm{C}+/-1^{\circ} \mathrm{C}\right)$ to limit deformation of the bitumen. After demolding the metal rings are cleaned using methylene chloride. The samples are now ready for assembly and stored again at $-24^{\circ} \mathrm{C}$ until assembly.

Assembly is performed in a temperature controlled room at $13^{\circ} \mathrm{C}+/-1^{\circ} \mathrm{C}$. First the samples are taken out of the freezer and left for 1 hour to gain temperature equilibrium. Specimens are assembled in small metal storage containers that ensure alignment during assembly and healing. The inside of the metal storage containers is covered with silicon paper to prevent sticking of bitumen to the container. First one piece of bitumen is placed in the container. Then a small round piece of silicon paper is placed in between the specimens to control the area in contact (see FIGURE 4 a.). Next, another sample is placed, upside down, on top of the first sample. When the samples are assembled a weight can be placed on the sample to investigate the impact of the load level during healing (see FIGURE $4 \mathrm{~b}$ ). The healing time is measured from the moment that the specimens are assembled. 
a.

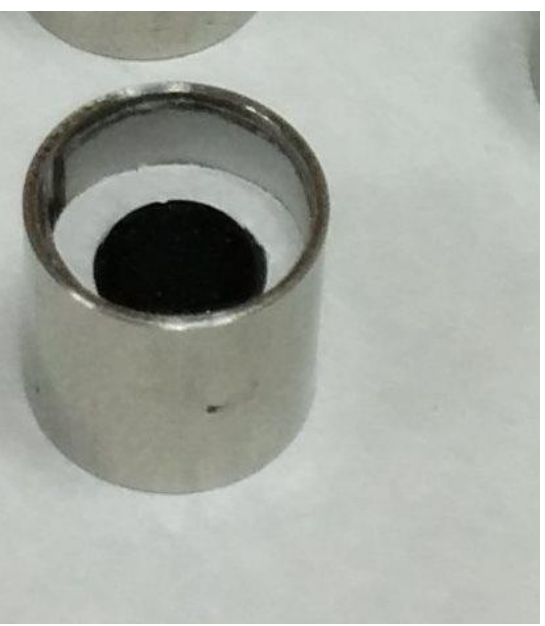

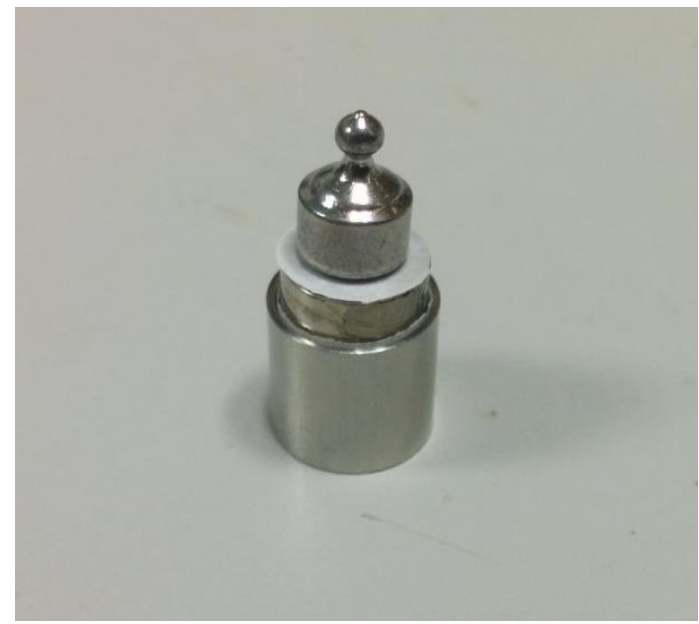

b.

3 FIGURE 4 a. Sample in Storage Container, Showing the Silicon Paper That Controls Contact Area d.

4 Assembled Test Specimen with Weight.

\section{Tensile Testing With DSR}

6 The samples are taken out of storage after the healing time has elapsed and are stored at $-2^{\circ} \mathrm{C}$ until

7 the moment of testing, which is maximum 24 hours later. The specimens are tested under 8 controlled temperature conditions at $10^{\circ} \mathrm{C}+/-0.2^{\circ} \mathrm{C}$. The assembled specimen is taken out of the 9 storage container and fixed with clamps in the DSR (FIGURE $5 \mathrm{a}$ ). The temperature is kept for 10 10 minutes at $10^{\circ} \mathrm{C}$. The sample is loaded in tension with a speed of $0.01 \mathrm{~mm} / \mathrm{s}$. After loading 11 interaction between the both specimens can clearly be observed from the failed specimen 12 (FIGURE 5 b).

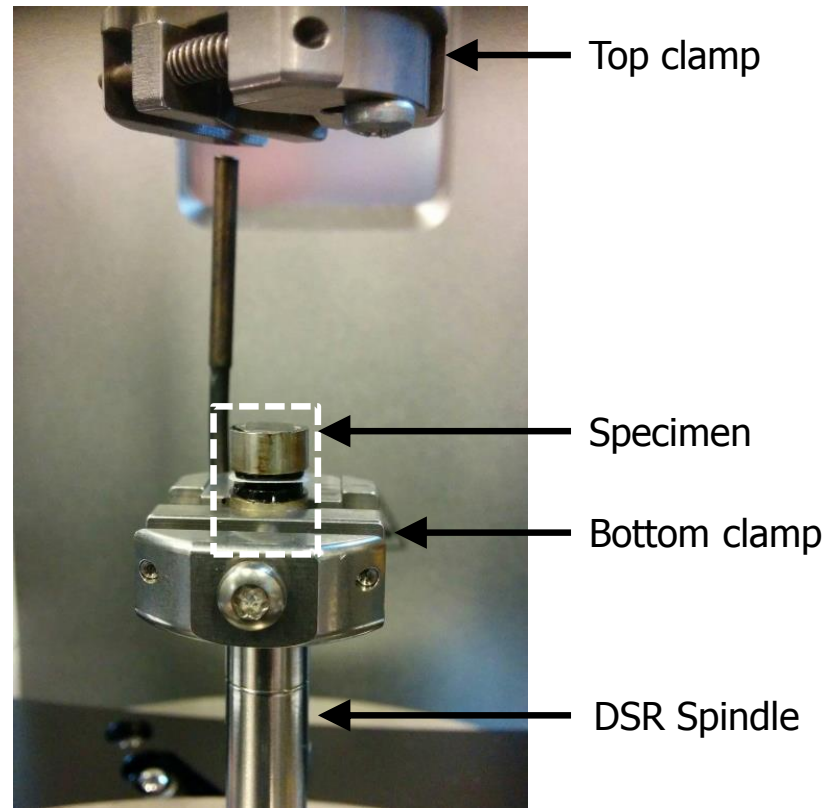

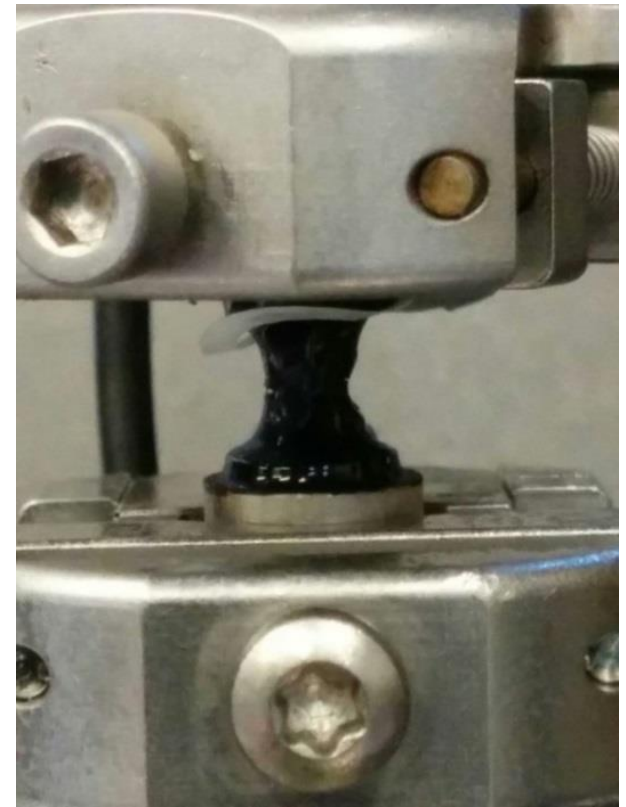

b.

15 FIGURE 5 a. Specimen Fixed in Bottom Clamp in DSR b. Specimen After Testing at $10^{\circ} \mathrm{C}$. 


\section{Test Program}

One test series has run to check if the described test method only measures intrinsic healing. Following the definition of intrinsic healing in the introduction, intrinsic healing is a diffusion process and should consequently be independent of the load level during healing [8]. To study the impact of the load level during healing a small variation has been applied on the load level. Samples were left to heal for 1 hour, during healing three load levels were applied; only self-weight (0.6gr); $1.0 \mathrm{gr}+$ self-weight and 2.0 gr. plus self-weight. These load levels translate to the following respective normal forces; $0.00024 \mathrm{~N} / \mathrm{mm}^{2}, 0.00065 \mathrm{~N} / \mathrm{mm}^{2}$ and $0.00106 \mathrm{~N} / \mathrm{mm}^{2}$.

To study the impact of healing time a series of samples was exposed to different healing times. The samples were loaded with 1 gram, healing times were ; 0.1 hour, 1 hour, 6 hours, 24 hours, 48 hours and 1 week. In this series no reference samples were used to test the capacity of intact specimens as no reference samples are designed at this point.

For each test three samples were fabricated, incidentally a specimen was damaged during handling; consequently the data presented in the next paragraph is the average of either 2 or 3 measurements.

\section{RESULTS}

\section{Impact of Normal Force During Healing}

The impact of variating the load level during healing is given in FIGURE 6. In the graph it can

clearly be seen that the load level has a measurable impact on the measured healing.

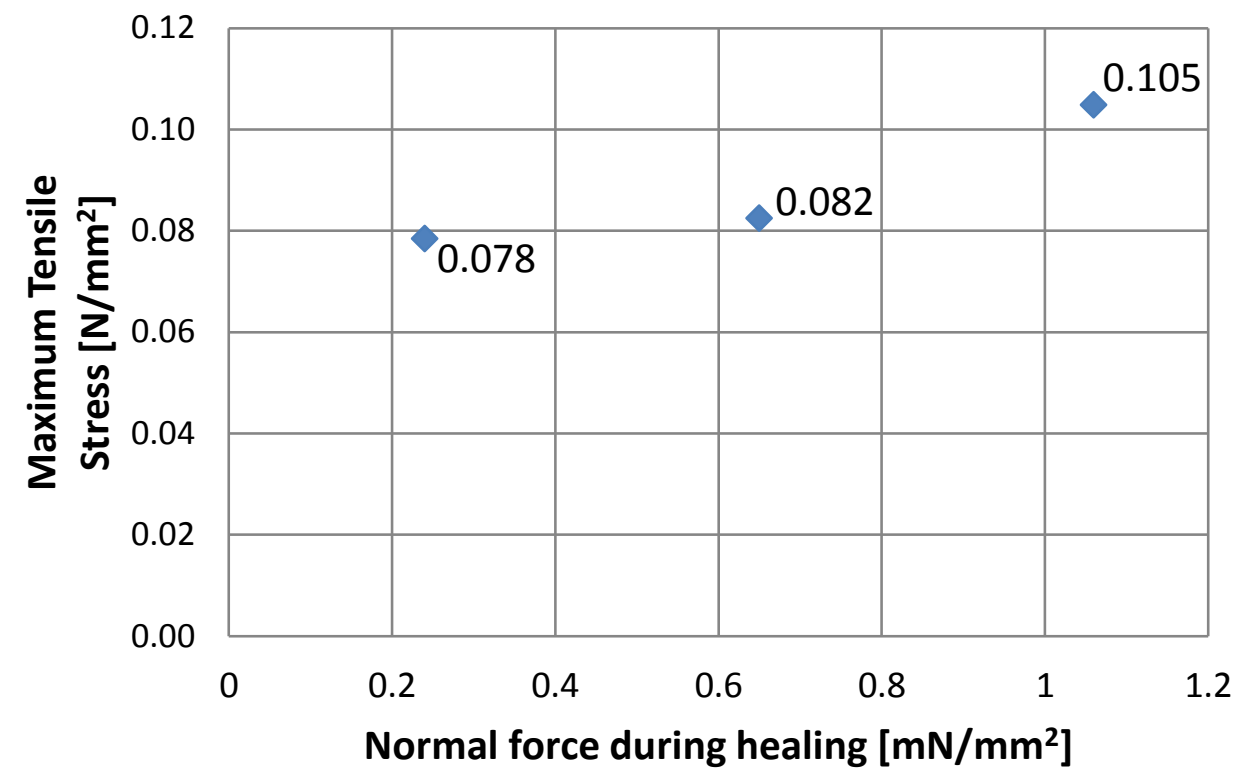

22 FIGURE 6 The Impact of Load Level during healing on measured healing

\section{Impact Healing Time}

24 The impact of healing time on the maximum tensile stress of the samples is presented in FIGURE 7. In the figure there is a clear development of tensile strength with healing time, to give some more detail in the short healing times it is chosen to present the data on a logarithmic time scale. It can be seen that at very short time $(0.1$ hour $)$ there already is a very significant level of tensile stress at failure. 


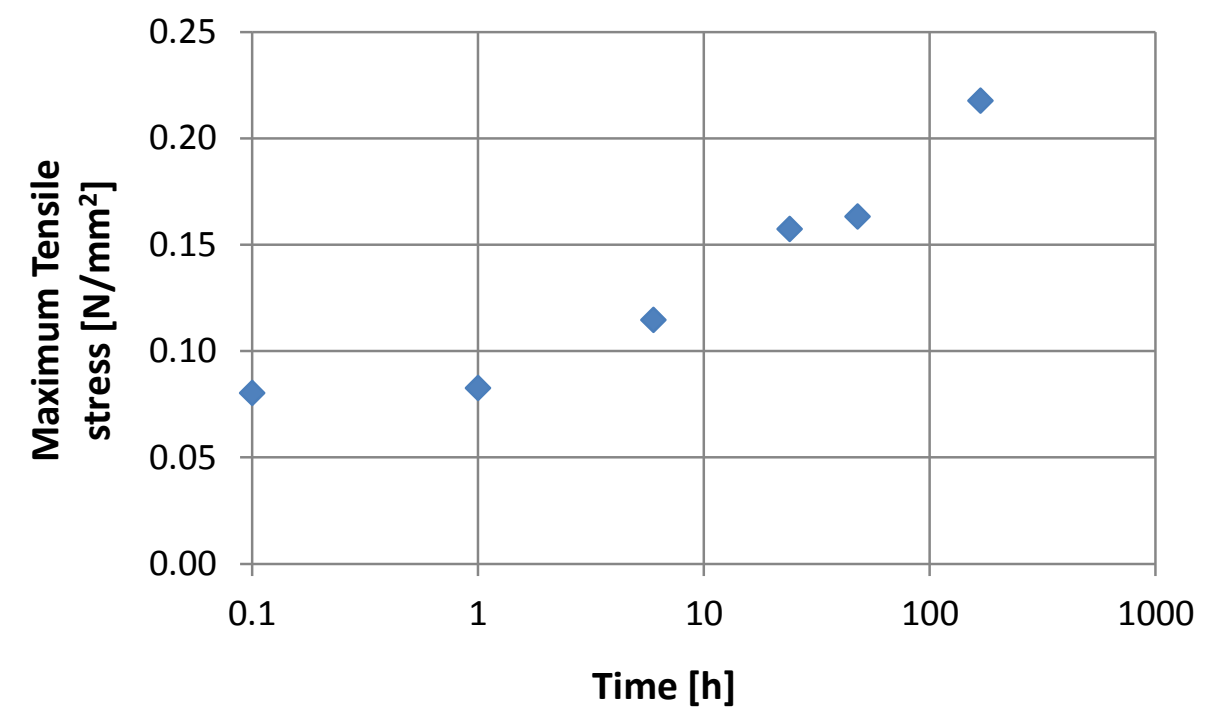

1

FIGURE 7 The Development of Maximum Tensile Stress for Increasing Healing Time

Relation Between Maximum Tensile Stress and Stiffness

4 Based on the load displacement curves, an analysis of the stiffness performed for measurements up 5 to 24 hours. In FIGURE 8 the relation between the measured stiffness and maximum tensile stress is shown. There is a very strong relation between the measured strength and the stiffness.

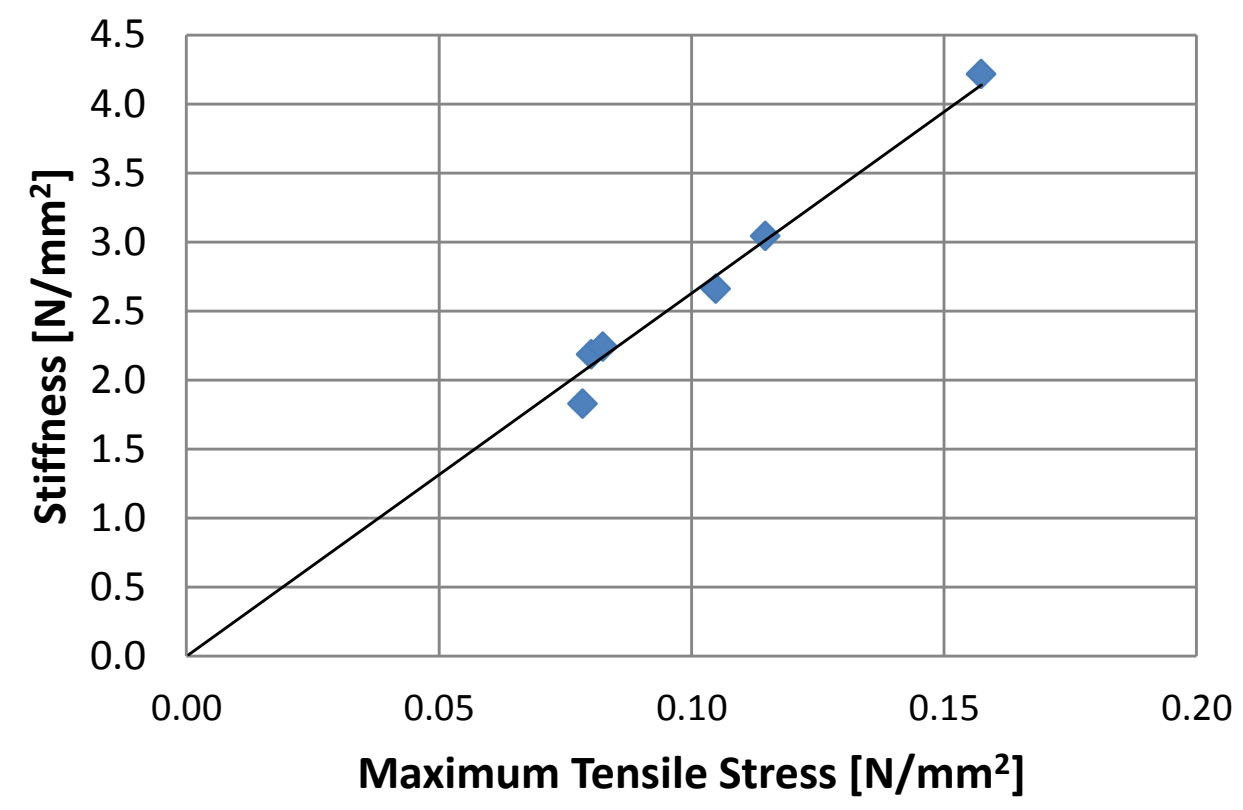

FIGURE 8 Maximum Tensile Stress Versus Stiffness

9 DISCUSSION OF RESULTS

10 Ability of The Method to Measure Intrinsic Healing

11 From FIGURE 6 it is clear that the force level has an impact on the maximum tensile stress. From 12 this it can be concluded that this test set-up does not measure purely intrinsic healing. As already 
stated intrinsic healing is related to diffusion, which is not influenced by the level of normal force. Consequently it can be concluded that healing measured is at least partly influenced by the wetting process. So even a very flat bitumen surface with no air bubbles detected by micro tomography does not ensure full instant wetting. Apparently bitumen has some micro/nano texture which impedes instant full wetting of two separate pieces of bitumen. This behavior matches with texture observations made with the Atomic Force Microscope on bitumen [13].

In this research the load level has been kept constant from the moment of assembly. In order to further study the impact of loading during healing a new test series will be set up. This series will explore separately the impact of load level at assembly and storage. The aim is to find an upper limit for the load level, above this level any additional load does not have any impact on the measured healing. If an upper limit can be found, the test method can be fine-tuned so that it will only measure intrinsic healing.

\section{Development of Healing Over Time}

As expected the amount of healing measured increases over time. From the reported changes over time two observations can be made. Firstly, the maximum tensile stress just after assembly at 0.1 hour (6 minutes) is fairly high, around 1/3 of the maximum tensile stress at 168 hours ( 1 week). From this is can be gathered that the instantaneous intrinsic healing makes up a significant part of the total observed healing for this bitumen. The second observation that can be made is the significant change in maximum tensile stress over a longer period of time (1 week), indicating that there are some slow processes also important for the extend of healing. To further explore the long term healing a new test series is proposed that monitors even longer healing times (or higher healing temperatures).

In the research no samples consisting of one piece of bitumen have been used as a reference. Consequently it is not possible to conclude what level of "healing" has been achieved at each time step, just a maximum tensile strain is reported. Due to aging and/or hardening any bitumen sample is expected to show an increase in maximum tensile force over time, so from the results presented it is not possible to assess which part of the increase in tensile stress can be attributed to healing and which to aging/hardening. Therefore in future test series non damaged reference samples will be used to be able to determine an actual healing level.

\section{Strength to Stiffness Ratio}

What is interesting to see from the data is the fact that the stiffness develops proportionally to the maximum tensile stress. Consequently, the presented data cannot help to explain the quick recovery of stiffness found in asphalt concrete compared to the strength recovery or the number of load cycles to failure.

\section{Healing as the Convolution of Wetting and Intrinsic Healing}

The data presented in this paper demonstrated that it is plausible that healing measured in bitumen is the convolution of wetting and intrinsic healing. In the development over time there it can be seen that different processes play a role as the data cannot easily be fit mathematically. This implies that it is very likely that two or more processes are driving the healing process. The realization that different processes play a role is very helpful for understanding the healing phenomenon. This insight can be used to vary parameters that only influence on of the processes and look for effects, to assess the relative impact of a specific process.

From the presented results is also becomes clear that it is very hard to test intrinsic healing separately, because it is complex to realize full instant contact of two surfaces. Therefore the 
1 quantitative use of the model might be limited as it is impossible to analyze the two processes

2 separately.

\section{CONCLUSION}

5 A test method has been developed that can test the healing of bitumen with respect to stiffness and 6 strength. In this test, direct tensile tests are performed on a specimen that is assembled out of two 7 separate pieces of bitumen. Specimens can heal under controlled conditions varying healing time, 8 normal force and temperature.

9 From the test results it can be seen that after a very short healing time of 6 minutes there is 10 already a significant amount of load that can be carried, so the cohesion of bitumen (or adhesion of 11 bitumen to bitumen) is an important factor which influences the healing capacity.

12 From the results it was also found that the maximum tensile stress increased significantly 13 over 1 week of healing. This indicated that also slow processes like diffusion have a significant 14 influence on healing.

The ratio between strength and stiffness of the observed healing of bitumen was constant. The results show the importance of considering healing as a combination of wetting and intrinsic healing, as is done with the convolution model for healing.

\section{OUTLOOK}

20 The test method and program presented here are the start of a larger investigation into healing of bitumen and mortar, which aims to improve fundamental insight into healing behavior of asphalt. In the near future tests are planned on to further explore the impact of test conditions as suggested in the discussion part of this paper, next to this different types of bitumen will be tested. For the longer time scale tests are planned on mortars and fatigued specimens.

\section{ACKNOWLEGDEMENTS}

27 The authors would like to express gratitude to InfraQuest, a Dutch collaboration initiative on

28 research in road engineering between Delft University of Technology, Rijkswatertstaat (Owner of

29 Dutch Highway network) and TNO. 


\section{REFERENCES}

1. Bazin, P. and J. Saunier. Deformability, fatigue and healing properties of asphalt mixes. in Intl Conf Struct Design Asphalt Pvmts. 1967.

2. Bonnaure, F., A. Huibers, and A. Boonders, A laboratory investigation of the influence of rest periods on the fatigue characteristics of bituminous mixes. Journal of the Association of Asphalt Paving Technologists, 1982. 51: p. 104-128.

3. Kim, Y.R., D.N. Little, and F.C. Benson, Chemical and mechenical evaluation on healing mechanism of asphalt concrete. Journal of the Association of Asphalt Paving Technologists, 1990. 59.

4. Bhasin, A., S. Palvadi, and D.N. Little, Influence of aging and temperature on intrinsic healing of asphalt binders. Transportation Research Record: Journal of the Transportation Research Board, 2011. 2207(1): p. 70-78.

5. $\quad$ Qiu, J., Self-Healing of Asphalt Mixtures 2012, Technical University Delft: Delft.

6. Di Benedetto, H., Q.T. Nguyen, and C. Sauzéat, Nonlinearity, heating, fatigue and thixotropy during cyclic loading of asphalt mixtures. Road Materials and Pavement Design, 2011. 12(1): p. 129-158.

7. Nahar, S., et al., Microstructural changes in bitumen at the onset of crack formation. European Polymer Journal, 2014. 56: p. 17-25.

8. Wool, R.P. and K.M. O' Connor, A theory crack healing in polymers. Journal of Applied Physics, 1981. 52(10): p. 5953-5963.

9. Little, D.N. and A. Bhasin, Exploring Mechanism of Healing in Asphalt Mixtures and Quantifying its Impact. Springer Series in Materials Science, 2007. 100: p. 205.

10. Hager, M.D., et al., Self - Healing Materials. Advanced Materials, 2010. 22(47): p. 5424-5430.

11. Kendall, K., Molecular adhesion and its applications: the sticky universe. 2001: Springer.

12. Lee, H.-J. and Y.R. Kim, Viscoelastic continuum damage model of asphalt concrete with healing. Journal of Engineering Mechanics, 1998. 124(11): p. 1224-1232.

13. Masson, J.F., V. Leblond, and J. Margeson, Bitumen morphologies by phase - detection atomic force microscopy. Journal of microscopy, 2006. 221(1): p. 17-29. 